\title{
Assessment of intelligence quotient score in children at the age of six with suspected congenital hypothyroidism: A retrospective cohort study
}

\author{
Shahin Saeidinejat ${ }^{1}$, Nosrat Ghaemi Belhouri ${ }^{2}$, Fahimhe Attarian*3 (ID
}

Received: 8 Jan 2019

Published: 9 Sep 2020

\section{Abstract}

Background: The clinical suspicion of Congenital Hypothyroidism $(\mathrm{CH})$ is identified by abnormal results in the first test of Thyroid Stimulating Hormone (TSH) (5-9.9 mIU/L), and normal results in re-test $(\mathrm{TSH}<4 \mathrm{mIU} / \mathrm{L})$. The $\mathrm{CH}$ has a contribution to physical and mental health. This study aimed to determine the Intelligence Quotient (IQ) score in children with suspected congenital hypothyroidism.

Methods: This research is a retrospective cohort study conducted in Mashhad, Iran. The IQ scores of 1976 children at the age of 6 were considered as an outcome variable. The history of $\mathrm{CH}$ screening for each newborn was assessed, then all suspected $\mathrm{CH}$ newborns that diagnosed healthy in re-test were considered as an exposed group, the effects of this situation on IQ score was assessed using logistic regression. All analysis was performed in STATA.

Results: The averages of IQ score $(p<0.001)$, weight $(p=0.024)$, and height $(p<0.001)$ in the exposed group were lower than the unexposed group. The exposed group was related to those whose parental education was less or equal to 12 years $(p<0.001)$. Similarly, the history of $\mathrm{CH}$ and maternal education for $\leq 12$ years were detected as risk factors for having an IQ score of $<90$ in children.

Conclusion: Aside from the link between parental education and clinical suspicion of $\mathrm{CH}$ in neonates, our findings underline the possible strong effect of $\mathrm{CH}$ status and maternal education for $\leq 12$ years on reducing IQ scores in the next years of child life.

Keywords: Intelligence quotient, Suspected CH newborn, Congenital hypothyroidism

Conflicts of Interest: None declared

Funding: Mashhad University of Medical Sciences

\section{*This work has been published under CC BY-NC-SA 1.0 license.}

Copyright $₫$ Iran University of Medical Sciences

Cite this article as: Saeidinejat Sh, Ghaemi Belhouri N, Attarian F. Assessment of intelligence quotient score in children at the age of six with suspected congenital hypothyroidism: A retrospective cohort study. Med J Islam Repub Iran. 2020 (9 Sep);34:117. https://doi.org/10.47176/mjiri.34.117

\section{Introduction}

Congenital hypothyroidism $(\mathrm{CH})$ is an important cause of intellectual disability (1-3). Accordingly, there is an

Corresponding author: Fahimhe Attarian, attarian.F@tak.iums.ac.ir

1. Department of Persian Medicine, School of Persian and Complementary Medicine, Mashhad University of Medical Sciences, Mashhad, Iran

2. Department of Pediatric Endocrinology and Metabolism, School of Medicine, Mashhad University of Medical Sciences, Mashhad, Iran

3. Student Research Committee, Department of Epidemiology, School of Public Health, Iran University of Medical Sciences, Tehran, Iran inverse relationship between intelligence quotient (IQ) and $\mathrm{CH}$ (4). The incidence of $\mathrm{CH}$ is different across the

\section{$\uparrow$ What is "already known" in this topic:}

Suspected newborns to congenital hypothyroidism will be considered as a healthy when their re-test result is normal, and they are omitted from follow up consequently. Clinical suspicion of Congenital Hypothyroidism may be raised due to congenital hypothyroidism or laboratory error. This congenital disease may impose an influence on physical health, mental health, and growth.

\section{$\rightarrow$ What this article adds:}

Parental education for $\leq 12$ years was related to the clinical suspicion of congenital hypothyroidism in newborns. This disease in neonates reduces mean weight and height at the age of 6 years old. Besides, clinical suspicion of $\mathrm{CH}$ and maternal education for $\leq 12$ years cause a low IQ score in children. Therefore, newborns without confirmed $\mathrm{CH}$ in re-test may display growth-related disorders within the next years of their life. 
world and is higher in Asians compared to American and European populations (5-10). Besides, it shows a difference between various regions in Iranian population (rang $1: 400$ to $1: 1000)(11-15)$. Main cause of $\mathrm{CH}$ is unknown(4). According to guidelines $(4,16)$, newborns with the level of thyroid-stimulating hormone (TSH) $>10 \mathrm{mu} / 1$ are considered as $\mathrm{CH}$ cases and they need to be under treatment with levothyroxine. However, TSH between 5 to 9.9 is classified as suspected $\mathrm{CH}(17,18)$, and a second specimen two weeks after birth is needed to be obtained (19). If the re-test result is normal ( $\mathrm{TSH}<5 \mathrm{mu} / \mathrm{l})$, there is no need for intervention, and newborns will be omitted from the follow up $(11,20)$. The Incidence of suspected $\mathrm{CH}$ in Iran is $3.46 \%$, most of which, are not confirmed in the re-test (21). The lack of confirmed $\mathrm{CH}$ cases may be related to minor disorders which result in a malfunction in congenital thyroid or can be caused by an error. However, there is still inadequate evidence for defining this status (19). Only a few retrospective studies suggest a decrease in IQ score a related factor for subclinical $\mathrm{CH}(20,22)$. Besides, children with a history of subclinical $\mathrm{CH}$ are at risk of behavioral problems and possible impaired growth(22), and this raises the possibility that children without a history of confirmed $\mathrm{SCH}$ may be exposed to similar risks $(20,23)$, although the over and undertreatment with levothyroxine itself can be considered a risk factor in $\mathrm{CH}$ children (24). This study aimed to determine the role of IQ score at the age of 6 in suspected newborns to congenital hypothyroid.

\section{Methods}

This was a retrospective cohort study conducted in Mashhad in 2018. In this study, we used data from a Preschool test, Intelligence Quotient (IQ) score, weight (kg) and height $(\mathrm{cm})$ for all children at age 6 . We used information of 1973 children whose parents announced their consent for participation in this study.

Demographic variables and health information such as the result of $\mathrm{CH}$ screening (history of Thyroid function in the first days of birth), mode of delivery; parent's age, and socioeconomic status (parent's education and job, family size) were extracted from health care cards for each child. Three children excluded from the analysis due to the lack of records for $\mathrm{CH}$ screening results.

The Wechsler Preschool and Primary Scale of Intelligence-Fourth Edition (WPPSI-IV) is the latest edition of the individually administered early childhood intelligence test. The full-scale IQ score is determined by a formula that adds both verbal and performance IQ scores. The Persian version of this tool shows high validity $(0.91)$ and reliability (0.76) (25). The full-scale IQ (FSIQ) which can be calculated by this tool, ranges from 45-155. ( a score beyond 130 is considered superior or "gifted", 120-129 is "very high", 110-119 are considered "bright normal", and anything less than 90 is considered low average) (26).

Based on the usual approach for $\mathrm{CH}$ screening in Iran, a few drops of blood is taken from the heel of the neonates, and then poured on a filter paper for analysis and measurement by using the enzyme-linked immune sorbent assay (ELISA) technique. According to the national protocol

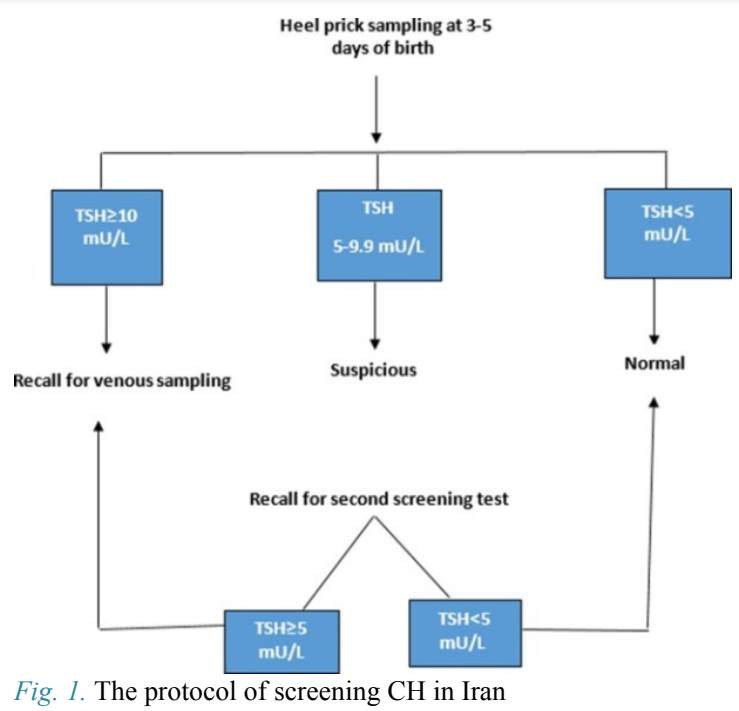

in Iran, a TSH level of $<5 \mathrm{~m} \mathrm{U/L}$ for neonates age 3-7 days is considered as normal. Other results are categorized as suspicious $(5<\mathrm{TSH}<9.9)$ and whose recall for venous sampling $(\mathrm{TSH}>10)$.Re-test is recommended for suspicious cases to be done (TSH range: $5-9.9 \mathrm{~m} \mathrm{U} / \mathrm{L}$ ). If the re-test shows a TSH $<5$, it is usually considered as a normal (healthy newborn), and this neonates omitted of the follow up (Fig. 1).

In this study, the children who were suspected for congenital hypothyroidism $(\mathrm{TSH}=5-9.9)$ in the first test, and normal in the re-test $(\mathrm{TSH}<5)$ were considered as an exposed group, while the non-exposed group had normal result in the first test $(\mathrm{TSH}<5)$. The mean-2SD was considered as a cut point to determine normal or abnormal IQ scores in two groups. Baseline variables were parent's education ( $\leq 12$ years or $>12$ years), parent's job (unemployed or others), family size $(\geq 4$ or $<3$ ), mode of delivery (vaginal delivery or cesarean section), and gender.

The proposal related to this study was approved by the ethical committee of Mashhad University of Medical Sciences (\#89102). The authors reported the overall results of the study.

\section{Statistical Analysis}

For data analysis, STATA statistical package, version12 (STATA Corporation, College Station, TX, USA, 2009) was used. Firstly, we described data by frequency, percentage, mean, and standard deviation; second, we used tTEST, Chi-square, or Fisher exact test to examine the associations of baseline categorical variables with outcomes. In the following, the risk factors for abnormal IQ were evaluated by the logistic regression model, covariates in crud analysis $(\mathrm{p}<0.2)$ were assessed by adjusted logistic regression for control of potential confounders. The Odds ratio estimated, and P-value 0.05 was considered statically significant for all tests.

\section{Results}

In a total of 1973 children, the distribution of gender was approximately equal, including girls $(n=996,50.43 \%)$ 
and boys ( $\mathrm{n}=977,49.57 \%)$. The incidence of suspected congenital hypothyroidism $(5<\mathrm{TSH}<9.9)$ was $3.18 \%$ (CI95\% 2.49, 4.06). However, all tests were in the normal range after the re-test $(\mathrm{TSH}<4)$. Accordingly, $70 \%$ of newborns were screened at the age of 3-5 days after birth, $10.6 \%$ at $6-40$ days, $0.6 \%$ at $>40$ days, and $18.7 \%$ of newborns were tested in less than 72 hours after birth.

The history of cesarean section delivery was detected in $52 \%$ and the mean of height was $117.76 \pm 5.82$ (range: 90 155 ). Similarly, the mean weight was $20.47 \pm 3.99$ (range: $10-45$ ), and the average IQ score was $98.49 \pm 4.77$ (range: 74-152). The IQ score was 98.18 (range: 97.89-98.48) and 98.79 (range: 98.49-99.09) in boys and girls, respectively. We considered a cut point of 89.99 to determine the normal IQ score in this data. IQ of $<90$ was found in99 $(5.03 \%)$ and IQ of $\geq 90$ in $1871(94.97 \%)$ participants.

\section{Characteristics of exposed and unexposed groups}

From a total of 1970 children with a history of $\mathrm{CH}$ screening result, 1906 had $\mathrm{TSH}<5$ (unexposed group) and
64 children had TSH 5-9.9 in the first test, and all was healthy in the re-test (exposed group). The baseline variables according to the exposed and unexposed group summarized in Table 1. The result indicated that there is a significant relationship between the level of parental education and level of TSH in newborns $(p<0.001)$, however, there is no relationship between parent's age and delivery mode with TSH level ( $p>0.05)$. In this cohort study, not only the average IQ score in the unexposed group was higher than the exposed group $(p<0.001)$, but also the mean difference of weight and height in the unexposed and exposed group was statistically significant $(\mathrm{p}<0.050)$. An unexposed group was heavier $(\mathrm{p}=0.028)$ and taller $(\mathrm{p}<0.001)$ than the exposed group (Table 1$)$.

Factors associated with abnormal IQ in children at age of 6 is presented in Table 2. The following factors were included in the logistic regression model: Parent's education ( $\leq 12$ years or $>12$ years), parent's job (unemployed or others), delivery mode (normal vaginal delivery or cesarean section), sex and $\mathrm{TSH} 1 \quad(\mathrm{TSH} \geq 5$ or $\mathrm{TSH}<4.99)$.

Table 1. Comparison of baseline characteristics in the exposed and unexposed group

\begin{tabular}{|c|c|c|c|c|c|c|c|}
\hline \multicolumn{2}{|l|}{ Variable } & \multicolumn{2}{|c|}{$\begin{array}{c}\text { Exposed group } \\
\mathrm{n}=64\end{array}$} & \multicolumn{2}{|c|}{$\begin{array}{l}\text { Unexposed group } \\
n=1906\end{array}$} & Total & $\mathrm{p}$ \\
\hline \multirow[t]{2}{*}{$\operatorname{Sex}(n \%)$} & Male & \multicolumn{2}{|c|}{$32(3.28 \%)$} & \multicolumn{2}{|c|}{$943(96.72 \%)$} & 975 & 0.944 \\
\hline & Female & \multicolumn{2}{|c|}{$32(3.23 \%)$} & \multicolumn{2}{|c|}{$960(96.77 \%)$} & 992 & \\
\hline \multirow[t]{2}{*}{ Delivery mode $(\mathrm{n} \%)$} & Cesarean & \multicolumn{2}{|c|}{$34(3.36 \%)$} & \multicolumn{2}{|c|}{$979(96.64 \%)$} & 1013 & 0.865 \\
\hline & Vagina & \multicolumn{2}{|c|}{$30(3.22 \%)$} & \multicolumn{2}{|c|}{$902(96.78 \%)$} & 932 & \\
\hline \multirow[t]{2}{*}{ Mother's education } & $\leq 12$ years & \multicolumn{2}{|c|}{$46(5.16 \%)$} & \multicolumn{2}{|c|}{$846(94.84 \%)$} & 892 & $<0.001$ \\
\hline & $>12$ years & \multicolumn{2}{|c|}{$16(1.53 \%)$} & \multicolumn{2}{|c|}{$1033(98.47 \%)$} & 1049 & \\
\hline \multirow[t]{2}{*}{ Father's education } & $\leq 12$ years & \multicolumn{2}{|c|}{$52(5.26 \%)$} & \multicolumn{2}{|c|}{$936(94.75 \%)$} & 988 & $<0.001$ \\
\hline & $>12$ years & \multicolumn{2}{|c|}{$12(1.25 \%)$} & \multicolumn{2}{|c|}{$947(98.75 \%)$} & 959 & \\
\hline \multirow[t]{2}{*}{ Mother's job } & Housewife & \multicolumn{2}{|c|}{$60(3.54 \%)$} & \multicolumn{2}{|c|}{$1633(96.46 \%)$} & 1693 & 0.082 \\
\hline & Others & \multicolumn{2}{|c|}{$3(1.34 \%)$} & $221(98$ & & 224 & \\
\hline Father's job & Unemployed & $1(2$. & & $35(97$. & & 36 & 0.860 \\
\hline & Others & $63(3$. & & $1842(96$ & & 1905 & \\
\hline Family size (mean \pm & & $4.31=$ & & $4.05 \pm$ & & & \\
\hline Mother's age (mean & & 32.68 & & $32.82 \pm$ & & & \\
\hline Father's age (mean \pm & & 36.49 & & $37.14 \pm$ & & & \\
\hline IQ score $($ mean $\pm \mathrm{SD})$ & & $86.01=$ & & $98.91 \pm 0$ & & & \\
\hline Weight $(\mathrm{kg})$ (mean \pm & & 19.35 & & $20.51 \pm$ & & & \\
\hline Height $(\mathrm{cm})($ mean \pm & & $114 \pm$ & & $117 \pm 0$ & & & \\
\hline variable & & & Unadju & & & Adjuste & \\
\hline & & $\overline{\mathrm{OR}}$ & $\bar{p}$ & CI 95\% & $\overline{\mathrm{OR}}$ & $\mathrm{p}$ & CI 95\% \\
\hline & $>12$ years & 1 & - & - & 1 & - & - \\
\hline Mother's education & $\leq 12$ years & 2.96 & $<0.001$ & $(1.47,3.55)$ & 2.30 & 0.014 & $(1.18,4.50)$ \\
\hline & $>12$ years & 1 & - & - & 1 & - & - \\
\hline Father's education & $\leq 12$ years & 2.28 & $<0.001$ & $(1.47,3.55)$ & 0.81 & 0.54 & $(0.42,1.58)$ \\
\hline & Others & 1 & - & - & 1 & - & - \\
\hline Mother's job & Housewife & 3.12 & 0.027 & $(1.13,8.58)$ & 2.04 & 0.25 & $(0.60,6.98)$ \\
\hline Father' job & Others & 1 & - & - & - & - & - \\
\hline & Unemployed & 1.12 & 0.877 & $(0.26,5.73)$ & - & - & - \\
\hline Mother's age & $\leq 35$ & 1 & - & - & - & - & - \\
\hline & $>35$ & 1.27 & 0.27 & $(0.82,1.98)$ & - & - & - \\
\hline Gender & girl & 1 & - & - & 1 & - & - \\
\hline & boy & 1.34 & 0.154 & $(0.89,2.02)$ & 1.63 & 0.08 & $(0.93,2.85)$ \\
\hline $\mathrm{TSH}_{1}$ & TSH $<4.99$ & 1 & - & - & 1 & - & - \\
\hline & $\mathrm{TSH} \geq 5$ & 151.85 & $<0.001$ & $(77.47,297.6)$ & 139.74 & $<0.001$ & $\begin{array}{l}(68.11 \\
284.7)\end{array}$ \\
\hline Delivery type & Vaginal & 1 & - & - & - & - & - \\
\hline & Caesarean & 1.04 & 0.834 & $(0.69,1.57)$ & - & - & - \\
\hline
\end{tabular}


After adjusting for other factors, TSH1 and Mother's education level were significantly associated with abnormal IQ $(p<0.001, p=0.014)$. On the other hand, odds of $a b-$ normal IQ were 139.74 times more likely in children with a history of TSH1 $>5$ compared to children with a history of normal neonatal TSH1 $(\mathrm{p}<0.001)$. Besides, odds of abnormal IQ were 2.30 times more likely in mothers who have education $\leq 12$ years compared to $>12$ years $(p=0.014)$. Other independent variables were not significantly correlated with abnormal IQ.

\section{Discussion}

We demonstrated an association between abnormal neonatal TSH and IQ score in the next years of life in children who were suspicious of congenital hypothyroid $(\mathrm{TSH}=5-9.9)$ in the first test and diagnosed healthy $(\mathrm{TSH}<4)$ in re-test.

Our findings indicated that children with a history of abnormal neonatal TSH have a lower average of weight and height at the age of 6 compared to the other children with normal history, besides, they have a greater risk for IQ score of less than 90, and these findings are in line with Calaciura and colleagues findings $(27,28)$. Thyroid hormone is essential for normal growth of fetus and infant (29). Therefore TSH disorder during early life may be related to the development of several central transmitter systems that leads to immutable morphological and biochemical abnormalities (28). Neonatal with low thyroid hormone levels (even only for few days) are at the high risk of the impaired developmental outcome, impairment of mental and physical growth $(30,31)$, and abnormal thyroid function $(13,32-34)$.

The results also showed that maternal education could have an impact on IQ score in children, as mothers with 'lower education had a greater risk of having a child with abnormal IQ score $(\mathrm{IQ}<90)$ at the age of 6-7. Obtained data is similar to the findings from the ELGAN cohort study. According to this study, children belongs to women with $\leq 12$ years of education have a high risk of a low IQ score at the age of 10 (2). Thus, available data are in line with other studies that have evidence of the relationship between parent's education and IQ scores in children (2, 35, 36).

Despite the previous studies which demonstrated that only father's education status affects TSH in newborns (37), evidence of our study suggests that parent's education status was related to TSH level in newborns, and mothers with lower education had more probability of having newborn with $\mathrm{TSH}>5 \mathrm{mIU} / \mathrm{L}$. In a study conducted in Tianjin-China, low maternal education was considered as a predictor of $\mathrm{CH}$ (38), and over time, mothers with higher educational status had a lower risk of bad perinatal outcomes (39). Furthermore, mothers who have a higher level of education may be more willing to utilize prenatal care services $(40,41)$, and are more prone to avoid harmful behaviors (42). Besides, they have better nutrition behaviors for themselves and their children (43). Most studies pay less attention to the role of maternal education as a risk factor than biological factors that can influence neonatal thyroid function $(44,45)$.
According to our findings, the incidence of clinical suspicion of $\mathrm{CH}$ was $3.18 \%$, while all cases were healthy in the re-test (100\% healthy). This is similar to the findings of a previous survey in Iran (21). Although there is controversy about unequal (10) or equal sex ratio (girl/boy) of $\mathrm{CH}$ (46), our results indicate an equal sex ratio for clinical suspicion of $\mathrm{CH}$ (girl: boy 1:1). On the other hand, the risk of clinical suspicion of $\mathrm{CH}$ is equal in both sexes of neonates (47). Despite some reports indicating for the association between Cesarean delivery and abnormal TSH in the newborn $(37,48,49)$, such relation was not confirmed in our study $(10,46,50)$.

\section{Study limitations}

The retrospective nature of data was a limitation in this study, for example, lack of information about family income and lifestyle for each child 6 years ago which may influence IQ score.

\section{Conclusion}

Aside from the association between parental education for $\leq 12$ years and clinical suspicion of $\mathrm{CH}$ status in neonatal, our findings underline the possible effect of clinical suspicion of $\mathrm{CH}$ status and maternal education for $\leq 12$ years on a reduced IQ score in the next years of child life.

\section{Acknowledgment}

The authors appreciate the help and support of those who have a contribution to collecting data, and acknowledge the Chancellor of Mashhad University of Medical science and Mashhad health centers that provide acceptable results of thyroid screening tests.

\section{Conflict of Interests}

The authors declare that they have no competing interests.

\section{References}

1. Deng K, He C, Zhu J, Liang J, Li X, Xie X, et al. Incidence of congenital hypothyroidism in China: data from the national newborn screening program, 2013-2015. J Pediatr Endocrinol Metab. 2018;31(6):601-8.

2. Joseph RM, O'shea TM, Allred EN, Heeren T, Kuban KK. Maternal educational status at birth, maternal educational advancement, and neurocognitive outcomes at age 10 years among children born extremely preterm. Pediatr Res. 2018;83(4):767.

3. Klein AH, Meltzer S, Kenny FM. Improved prognosis in congenital bypothyroidism treated before age three months. J Pediatr. 1972;81(5):912-5.

4. Saran S. Congenital Hypothyroidism. Thyroid Disorders: Intech Open; 2019

5. Rosenthal M, Addison GM, Price DA. Congenital hypothyroidism: increased incidence in Asian families. Arch Dis Child. 1988 Jul;63(7):790-3.

6. Chiesa A, Prieto L, Mendez V, Papendieck P, de Luján Calcagno M, Gruñeiro-Papendieck L. Prevalence and etiology of congenital hypothyroidism detected through an argentine neonatal screening program (1997-2010). Horm Res Paediatr. 2013;80(3):185-92.

7. LaFranchi SH. Increasing incidence of congenital hypothyroidism: some answers, more questions. Oxford University Press; 2011.

8. Nascimento ML. Current situation of neonatal screening for congenital hypothyroidism: criticisms and perspectives. Arq Bras Endocrinol. 2011;55(8):528-33.

9. Ford G, LaFranchi SH. Screening for congenital hypothyroidism: a worldwide view of strategies. Best Pract Res Clin Endocrinol Metab. 
2014;28(2):175-87.

10. Donbaloğlu Z, Savaş-Erdeve Ş, Çetinkaya S, Aycan Z. Cases Referred from the Turkish National Screening Program: Frequency of Congenital Hypothyroidism and Etiological Distribution. J Clin Res Pediatr Endocrinol. 2019 Sep;11(3):240.

11. Veisani Y, Sayehmiri K, Rezaeian S, Delpisheh A. Congenital hypothyroidism screening program in iran; a systematic review and metaanalysis. Iran J Pediatr. 2014;24(6):665.

12. Dorreh F, Chaijan PY, Javaheri J, Zeinalzadeh AH. Epidemiology of congenital hypothyroidism in Markazi Province, Iran. J Clin Res Pediatr Endocrinol. 2014;6(2):105.

13. Rahmani K, Yarahmadi S, Etemad K, Mehrabi Y, Aghang N, Koosha A, et al. Intelligence Quotient at the Age of Six years of Iranian Children with Congenital Hypothyroidism. Indian Pediatr. 2018;55(2):121-4.

14. Hashemipour M, Amini M, Iranpour R, Sadri GH, Javaheri N, Haghighi S, et al. Prevalence of congenital hypothyroidism in Isfahan, Iran: results of a survey on 20,000 neonates. Horm Res Paediatr. 2004;62(2):79-83.

15. Karamizadeh Z, Saneifard H, Amirhakimi G, Karamifar H, Alavi M. Evaluation of congenital hypothyroidism in Fars province, Iran. IJP. 2012;22(1):107.

16. Rastogi MV, LaFranchi SH. Congenital hypothyroidism. Orphanet J Rare Dis. 2010;5(1):17.

17. Kilberg MJ, Rasooly IR, LaFranchi SH, Bauer AJ, Hawkes CP. Newborn screening in the US may miss mild persistent hypothyroidism. J Pediatr. 2018;192:204-8.

18. Jayasuriya MS, Choy KW, Chin LK, Doery J, Stewart A, Bergman $\mathrm{P}$, et al. Reference intervals for neonatal thyroid function tests in the first 7 days of life. J Pediatr Endocrinol Metab. 2018;31(10):1113-6.

19. Vigone MC, Capalbo D, Weber G, Salerno M. Mild Hypothyroidism in Childhood: Who, When, and How Should Be Treated. J Endocr Soc.. 2018;2(9):1024-39.

20. Langham S, Hindmarsh P, Krywawych S, Peters C. Screening for congenital hypothyroidism: comparison of borderline screening cutoff points and the effect on the number of children treated with levothyroxine. Eur Thyroid J. 2013;2(3):180-6.

21. Mehran L, Khalili D, Yarahmadi S, Delshad H, Mehrabi Y, Amouzegar A, et al. Evaluation of the congenital hypothyroidism screening programme in Iran: a 3-year retrospective cohort study. ADC Fetal Neonatal. 2018:fetalneonatal-2017-313720.

22. Grosse SD, Van Vliet G. Prevention of intellectual disability through screening for congenital hypothyroidism: how much and at what level. Arch Dis Child. 2011;96(4):374-9.

23. Calaciura F, Motta RM, Miscio G, Fichera G, Leonardi D, Carta A, et al. Subclinical hypothyroidism in early childhood: a frequent outcome of transient neonatal hyperthyrotropinemia. J Clin Endocrinol Metab. 2002;87(7):3209-14

24. Hauri-Hohl A, Dusoczky N, Dimitropoulos A, Leuchter RH-V, Molinari L, Caflisch J, et al. Impaired neuromotor outcome in schoolage children with congenital hypothyroidism receiving early highdose substitution treatment. Pediatr Res. 2011;70(6):614.

25. Sadeghi.A RM, Abedi.M. Reza. Validation and Reliability of the Wechsler Intelligence Scale for Children- IV. Dev Psychol. 2011;7(28):377-86.

26. Wechsler D. Wechsler preschool and primary scale of intelligencefourth edition. The Psychological Corporation San Antonio, TX. 2012.

27. Calaciura F, Mendorla G, Distefano M, Castorina S, Fario T, Motta $\mathrm{RM}$, et al. Childhood IQ measurements in infants with transient congenital hypothyroidism. Clin Endocrinol. 1995;43(4):473-7.

28. Ahmed OM, El-Gareib A, El-Bakry A, El-Tawab SA, Ahmed R. Thyroid hormones states and brain development interactions. Int $\mathrm{J}$ Dev Neurosci. 2008;26(2):147-209.

29. Eerdekens A, Naulaers G, Ortibus E, Verhaeghe J, Langouche L, Vanhole C. Evolution of circulating thyroid hormone levels in preterm infants during the first week of life: perinatal influences and impact on neurodevelopment. J Pediatr Endocrinol Metab. 2019;32(6):597-606

30. Iijima S. Current knowledge of transient hypothyroxinemia of prematurity: to treat or not to treat. J Matern Fetal Neonatal Med. 2019;32(15):2591-7

31. van Wassenaer AG, Briët JM, van Baar A, Smit BJ, Tamminga P, de Vijlder JJ, et al. Free thyroxine levels during the first weeks of life and neurodevelopmental outcome until the age of 5 years in very preterm infants. Pediatrics. 2002;110(3):534-9.

32. Eugène D, Djemli A, Van Vliet G. Sexual dimorphism of thyroid function in newborns with congenital hypothyroidism. J Clin Endocrinol Metab. 2005;90(5):2696-700.

33. Leonardi D, Polizzotti N, Carta A, Gelsomino R, Sava L, Vigneri R, et al. Longitudinal study of thyroid function in children with mild hyperthyrotropinemia at neonatal screening for congenital hypothyroidism. J Clin Endocrinol Metab. 2008;93(7):2679-85.

34. Banigé M, Polak M, Luton D, Benachi A, Biran V, Mokhtari M, et al. prediction of Neonatal Hyperthyroidism. J Pediatr. 2018;197:24954. e1.

35. Lean RE, Paul RA, Smyser CD, Rogers CE. Maternal intelligence quotient (iq) predicts Iq and language in very preterm children at age 5 years. J Child Psychol Psychiatry. 2018;59(2):150-9.

36. Farah MJ. Socioeconomic status and the brain: prospects for neuroscience-informed policy. Nat Rev Neurosci. 2018:1.

37. Rezaeian S, Poorolajal J, Moghimbegi A, Esmailnasab N. Risk factors of congenital hypothyroidism using propensity score: a matched case-control study. J Res Health Sci. 2013;13(2):151-6.

38. Leng J, Shao P, Zhang S, Li N, Pan L, Liu H, et al. Maternal education and newborn thyroid-stimulating hormone level in a congenital hypothyroidism screening program. J Matern Fetal Neonatal Med. 2018:1-5.

39. Juárez S, Revuelta-Eugercios BA, Ramiro-Fariñas D, VicianaFernández F. Maternal education and perinatal outcomes among Spanish women residing in southern Spain (2001-2011). Matern. Child Health J. 2014;18(8):1814-22.

40. Erci B. Barriers to utilization of prenatal care services in Turkey. JNS. 2003;35(3):269-73.

41. Elo IT. Utilization of maternal health-care services in Peru: the role of women's education. Health Transit Rev. 1992 Apr 1:49-69.

42. Ergin I, Hassoy H, Tanik FA, Aslan G. Maternal age, education level and migration: socioeconomic determinants for smoking during pregnancy in a field study from Turkey. BMC Public Health. 2010;10(1):325

43. Saleem AF, Mahmud S, Baig-Ansari N, Zaidi AK. Impact of maternal education about complementary feeding on their infants' nutritional outcomes in low-and middle-income households: a community-based randomized interventional study in Karachi, Pakistan. J Health Popul Nutr. 2014;32(4):623.

44. Hashemipour M, Samei P, Kelishadi R, Hovsepian S, Hani Tabaei Zavareh N. A Systematic Review on the Risk Factors of Congenital Hypothyroidism. J Pediatr Rev. 2019;7(4):199-210.

45. Dalili S, Rezvany SM, Dadashi A, Medghalchi A, Mohammadi H, Dalili $\mathrm{H}$, et al. Congenital hypothyroidism: a review of the risk factors. Acta Med Iran. 2012:735-9.

46. Zhang Y, Du C, Wang W, Chen W, Shao P, Wang C, et al. Effect of maternal and neonatal factors on neonatal thyroid stimulating hormone: Results from a population-based prospective cohort study in China. J Trace Elem Med Biol. 2018;49:151-6.

47. DeMartino L, McMahon R, Caggana M, Tavakoli NP. Gender disparities in screening for congenital hypothyroidism using thyroxine as a primary screen. Eur J Endocrinol. 2018;179(3):161-7.

48. Hazar N, Malamiri MJ, Tafti MRS, Ordooei M. Congenital Hypothyroidism in Yazd: Is It Really Prevalent. Acta Med Iran. 2018;56(4):261-6

49. Wang Y, He Y, Zhuang L, Li X, Chen T, Chen L, et al. Effect of Maternal and Neonatal Factors on Neonatal Thyroid Screening Results. Clin Lab. 2018;64(9):1445-50.

50. Baridkazemi S, Bahrami HR, Eftekhari Gol R, Mosa Farkhani E, Hoseini SJ. Investigation of the Risk Factors for Congenital Hypothyroidism in Iran: A Population-Based Case-Control Study. Ini J Pediatr. 2019;7(2):8951-8. 